\title{
Entre o Tráfico Humano e a Opção da Mobilidade Social: os Imigrantes Bolivianos na Cidade de São Paulo
}

\author{
Maria Cristina Cacciamali e \\ Flávio Antonio Gomes de Azevedo*
}

Resumo: A proposta deste artigo é examinar as singularidades e os desafios enfrentados pela comunidade boliviana que, na busca de melhores condições de vida, submete-se ao tráfico humano e ao trabalho indocumentado na Região Metropolitana de São Paulo. Na primeira parte introduzimos o problema e o perfil dessa comunidade. Em seguida, analisamos o conceito de tráfico humano e seus desdobramentos. A terceira parte apresenta uma breve história da inserção dos bolivianos nas oficinas de confecção. Dentre as principais conclusões, destacamos que, urge retirar as barreiras à mobilidade de mão-de-obra entre nações tanto para permitir a diminuição das desigualdades sociais quanto para combater a prática do tráfico humano.

Palavras-chave: Tráfico Humano, Trabalho Forçado, Bolivianos, Confecções, Imigração Internacional.

Abstract: The proposal of this article is to investigate particularities and challenges faced by the Bolivian community which, in the search for better living conditions, is subjected to human traffic and undocumented labor in the Metropolitan Region of São Paulo. In the first part we introduce the problem and the profile of this community. Subsequently, we analyze the concept of different processes of human traffic and its outcomes. The third part presents a brief history of the insertion of the Bolivians into clothes manufactories. Among the main conclusions we highlight that in a world, it is urgent to remove barriers to workforce mobility among nations in order to both permit the diminishment of social inequalities and combat the human traffic practice.

Keywords: Human Traffic, Forced Labor, Bolivians, Clothes Factories, International Immigration.

\footnotetext{
* Os autores são membros do Núcleo de Estudos e Pesquisa de Política Internacional-NESPI/USP -CNPq. Respectivamente, Professora Titular da FEA e do Programa de Pós-Graduação em Integração da América Latina (PROLAM) da Universidade de São Paulo (USP) e Mestre pelo PROLAM/USP. A pesquisa que deu origem a este artigo foi desenvolvida no âmbito do NESPI/USP-CNPq, e concluída sob a forma de Dissertação de Mestrado defendida no PROLAM/USP no ano de 2005 por Flávio Antonio Gomes de Azevedo . E-mail: cciamali@uol.com.br e fagaps@yahoo.com. Recebido em 15/04/06 e aceito em 01/06/06.
} 


\section{Introdução}

A comunidade boliviana na cidade de São Paulo pode reunir até 100 mil pessoas pelas estimativas da Pastoral dos Migrantes Latino-americanos, embora o consulado da cidade de São Paulo reconheça a existência de 50 a 70 mil imigrantes clandestinos. ${ }^{1}$ Dentre os seus membros estima-se que um terço se constitui de profissionais liberais, comerciantes e donos de oficina, enquanto dois terços representam trabalhadores clandestinos, denominados também de indocumentados, muitos trabalhando como costureiros em oficinas de confecção. A maioria dos imigrantes é do sexo masculino, não ou pouco qualificado, entre 20 e 40 anos, a idade melhor do ponto de vista produtivo.

A Bolívia se constitui em um pólo de emigração de mão-de-obra, pela baixa expectativa de desenvolvimento que se origina de sua estrutura social e econômica, pela instabilidade política e pela miséria de determinadas regióes. O Brasil e a Argentina constituem-se em pólos receptores dos emigrantes mais pobres devido ao menor custo de transporte relativamente aos países centrais e a extensa fronteira que separa a Bolívia dos dois países. As sucessivas crises econômicas e sociais da Argentina desde meados da década de 1990 redirecionam e intensificam o fluxo de emigração para o Brasil.

A Pastoral dos Migrantes Latino-americanos e o Centro de Estudos Migratório são duas organizações que mantêm informaçóes valiosas para compreender o fluxo e as características da emigração dos andinos para o Brasil. ${ }^{2}$ A Pastoral, além de sediar encontros e festas, mantém um serviço de atendimento para essa comunidade, proporcionando esclarecimentos sobre os procedimentos para conseguir a documentação necessária, e mediando conflitos no trabalho, por exemplo, quando o empregador não paga os salários. ${ }^{3}$

A partir dos dados obtidos através de entrevistas nessas duas instituiçóes e

\footnotetext{
${ }^{1}$ A Pastoral dos Migrantes Latino-americanos busca acolher e acompanhar o migrante prestando atendimento de acolhida, acompanhamento sócio-jurídico e religioso. http://www.cpmigrantes.com.br/quemsomos.htm

${ }^{2}$ O Centro de Estudos Migratórios (CEM) surgiu em 1969. Pertence à Congregação dos Missionários de São Carlos/ Escalabrianos, a sua finalidade é atuar junto aos migrantes. Integra a Federação de Estudos Migratórios João Batista Scalabrini, que congrega os demais Centros de Estudos da Congregação, presentes em vários países (São Paulo, Nova York, Paris, Roma, Buenos Aires, e Manila). Conta com uma biblioteca especializada e desde 1998 publica Travessia - Revista do Migrante. http://www.cemsp.com.br

${ }^{3}$ Dado obtido da entrevista com Padre Sidnei Marco DORNELAS realizada por AZEVEDO, Flávio Antonio Gomes de; MARQUE, Roberta Vaz de no Centro de Estudos Migratório da Pastoral dos Migrantes Latino-americanos.
} 
com imigrantes bolivianos clandestinos contatados nas ruas na cidade de São Paulo passamos a elaborar a tese de que a maioria dos imigrantes bolivianos que trabalha na condição de costureiro nas oficinas de confecção enfrenta o dilema de sujeitar-se ao tráfico humano para poder ambicionar melhores condiçóes de vida.

\section{Conceito de tráfico humano e os seus desdobramentos}

Contemporaneamente o crescente deslocamento humano significa um dos maiores dilemas a ser enfrentado em todo o globo. A intensificaçáo dessa prática entre os países latino-americanos, não é muito dispare do contexto internacional. As vítimas em geral oriundas de países vizinhos transformamse em imigrantes ilegais. Na maioria das vezes, elas emigram com esquemas montados por agências de viagem ou atravessadores, podendo contar com o apoio de familiares.

Comumente, a motivação, direta ou indiretamente, está associada à possibilidade de ascensão social, portanto, é pouco relevante que a relação de emprego seja coerciva ou voluntária. Porém, devido à condição de ilegalidade, os imigrantes acabam se submetendo ao confinamento e são coagidos a trabalhar mediante ameaças de denúncia e deportação.

A simples facilitação de entrada ilegal, em qualquer território não pode ser diretamente associada ao tráfico humano. O tráfico humano é caracterizado por pessoas que ultrapassam fronteiras e logo após mediante coerção, fraude ou força estarão sujeitas a um tipo de exploração ou de abuso. Indiferentemente de como a pessoa adentra no país de destino, se por meios legais ou não, existe por parte de outrem uma intenção prévia de exploração ou de abuso.

O tráfico humano ocorre quando há uma motivação da vítima para emigrar, podendo ser a busca da mobilidade social devido ao desemprego, por exemplo, ou a fuga de perseguição política, problemas policiais, familiares outros. Por outro lado, é necessária a presença de intermediários, recrutadores, agentes, empreendedores e até de redes do crime organizado, que por um lado agem no imaginário das vítimas, contribuindo para a formação de suas expectativas positivas para emigrar, e por outro, conduzem-nas ao local de destino.

Nesse sentido, o aliciador busca engajar pessoas em atividades e/ou 
trabalhos nada afeitos às normas laborais, tendo como único propósito a sua exploração. Freqüentemente, as vítimas são enganadas e incitadas com promessas de uma vida melhor, através das mais variadas ofertas de emprego. Porém, uma vez deslocadas para o local do emprego e isoladas podem ver cerceadas a sua liberdade. As vítimas em geral se percebem envolvidas em servidão por dívida, submetendo-se à prostituição, outras formas de exploração sexual, e ao trabalho forçado, em uma condição análoga à da escravidão, podendo estar sujeitas ao tráfico ilegal de órgãos. ${ }^{4}$

O tráfico humano produz a exploração de suas vítimas, não apenas pela condição de ilegalidade na qual elas passam a estar circunstanciadas, mas também pelo fato de ser este o seu desdobramento natural. Uma vez as vítimas enredadas nesse processo, elas são consideradas perante a lei como infratoras. Há também o fato de tratar-se de organizaçóes complexas e aparatadas de conexões internacionais, capazes de atuar em distintas regiōes que perfazem o trajeto do deslocamento clandestino.

O tráfico humano enquanto contravenção demanda uma alta capacidade de interação com outros grupos também vinculados ao crime organizado, principalmente oriundo de países exportadores de drogas. ${ }^{5}$ Exige também

\footnotetext{
${ }^{4}$ A servidão por dívida caracteriza-se pelo impedimento da vítima poder deixar o seu trabalho ou a terra onde trabalha até que sua dívida seja quitada. Ou seja, trabalhadores, podem ser privados de sua liberdade por dívidas contraídas com adiantamentos por agentes de recrutamento e transporte, muitas vezes empreiteiros de mão-de-obra para proprietários de terras ou para outros setores. Em outras regiões isoladas, os trabalhadores não têm outra alternativa senão o endividamento para a aquisição de alimentos e outros artigos de primeira necessidade que lhes são fornecidos pelo proprietário ou pelo recrutador, ou aceitar bens em vez de salários, mais conhecido como sistema de pagamento sob a forma de mercadorias. A retenção física e a força também são empregadas, muitas vezes, contra trabalhadores rurais apanhados nessas situações de servidão por dívida. As dívidas se acumulam às vezes com o financiamento para pagamentos de dotes, casamentos, funerais, e outras cerimônias que têm de ser pagas com a futura colheita (ORGANIZAÇÃO INTERNACIONAL DO TRABALHO - OIT, 2001, p. 22).

${ }^{5} \mathrm{O}$ juiz de Direito José Berlange Andrade acredita que o narcotráfico está diretamente relacionado com a miséria da população. Ele atua há 4 anos na comarca de Terenos, cidade sul-mato-grossense onde tramita o maior volume proporcional de processos de apreensão de drogas e prisão em flagrante das chamadas "mulas do tráfico" (homens que transportam drogas no corpo), em virtude da ação do posto da Polícia Rodoviária Federal localizado na BR-262, rodovia que liga Corumbá a Campo Grande. De acordo com o juiz, a partir de dezembro de 2004 houve aumento no número de prisões de pessoas com drogas no corpo. Ele acredita que isso ocorreu com a entrada em vigor da Lei do Abate, que autoriza a Aeronáutica brasileira a abater aviões clandestinos, geralmente utilizados por traficantes para o transporte de grandes quantidades de drogas para dentro do país. Segundo Berlange a saída encontrada pelos traficantes foi fomentar o transporte de drogas via terrestre. Para isso, houve, conforme o magistrado, aumento na atividade desenvolvida por mulashumanas. "Se não tem jeito de ir pelo ar, o tráfico é feito pelo chão", afirma. Conforme análise do juiz, "geralmente as pessoas que atuam como mulas têm o mesmo perfil social... Enquanto houver miséria, o tráfico continuará com as mulas". Texto Roberto Alexandre, in: http://www.folhadaregiao.com.br/rota_das_mulas/5.php
} 
margens de manobra para assegurar a sua obscuridade, por exemplo, grande variedade de rotas alternativas, capacidade de corromper a guarda da fronteira e um forte poder de coerção para manter suas vítimas em silêncio.

$\mathrm{O}$ tráfico humano conta com dispositivos que envolvem várias etapas. $\mathrm{O}$ recrutamento - ocorre no país de origem, de trânsito ou de destino através de um indivíduo ou agência de recrutamento de caráter legal, semi-legal ou falseamento legal que buscam persuadir o indivíduo a atravessar a fronteira apenas com o intuito de sua exploração. $O$ transporte - compreende meios variados de locomoção e facilitação de entrada nas fronteiras. A transferência - envolve indivíduos que facilitem o tráfico no trânsito entre os países. O refúgio/abrigo - deve existir nos locais de trânsito. E, a receptaçáo de pessoas - que verifica no destino final, ou melhor, no local para a exploração. As vítimas são mantidas em situação de exploração por mecanismos de coerção: exercendo ameaças e o uso da força, restriçóes físicas à liberdade de movimento, abusos, violência, fraude, cativeiro, confisco de documentos, entre outros.

Devido a sua natureza transnacional, aos seus dispositivos e mecanismos de ocorrência e ao seu alto grau de complexidade, o tráfico de pessoas e/ou o contrabando de imigrantes encontra-se diretamente associado ao trabalho forçado no meio urbano. É um mal de difícil enfrentamento, requerendo para o seu combate à açáo conjunta dos países de origem, de trânsito e de destino.

Uma questão bem documentada refere-se ao fato que as estruturas legais de muitos países vêem os imigrantes clandestinos mais como criminosos do que como vítimas, ressaltando o seu envolvimento com a ilegalidade, e tratando-os como infratores das leis de imigração.

\section{Bolivianos que trabalham nas oficinas de confecção na cidade de São Paulo}

Tradicionalmente no Brasil, assim como em outros países, a indústria do vestuário se utiliza de mão-de-obra imigrante clandestina. A comunidade judia lidera essa atividade na cidade de São Paulo ao longo do século XX até a década de 1970, iniciando a contratação de mão-de-obra coreana clandestina em torno de 1960. Fluxos migratórios ampliam a comunidade coreana até o final dos anos de 1970, prosperando e passando a liderar essa 
atividade no Município de São Paulo, empregando o trabalho clandestino de seus compatriotas (KEUM, 1991).

Quando cessa o fluxo de emigração coreana, inicialmente os empregadores do setor contratam mão-de-obra nordestina, que não se adapta nem ao ritmo, nem às condiçóes de trabalho que lhes são impostas. Os trabalhadores nordestinos são cidadãos brasileiros, encontram-se protegidos pela legislação trabalhista e freqüentemente recorrem à Justiça do Trabalho para obter os seus direitos trabalhistas, em especial as horas-extras. ${ }^{6}$

A indústria de vestuário é altamente competitiva tanto domesticamente quanto no cenário do comércio internacional, caracterizando-se por poucas barreiras à entrada e por uma oferta de mão-de-obra infinitamente elástica, considerando-se os diferentes fluxos de emigração originários dos países periféricos. A redução dos custos através do rebaixamento dos salários, e de quaisquer outros custos indiretos de mão-de-obra, é freqüentemente empregada nessa atividade.

Por outro lado, a liberalização econômica e comercial da Argentina, do Brasil e da Bolívia, desde os anos de 1980, cria um ambiente propício tanto para a informalidade, quanto para a aceleração dos fluxos de emigração para os países mais ricos. ${ }^{7} \mathrm{O}$ agravo da concentração da renda, da pobreza e do desemprego, aliados ao empobrecimento dos estratos sociais médios passa a impulsionar ondas de emigração dos países periféricos para os países mais ricos. Os grupos bolivianos mais pobres, em virtude do custo de transporte e das facilidades de fronteira emigram para a Argentina e o Brasil e, a partir da segunda metade dos anos de 1990, após o prenúncio do declínio da economia Argentina, emigram principalmente para o Brasil (PATARRA, 1995).

A opção dos empregadores coreanos da cidade de São Paulo tendo

\footnotetext{
${ }^{6}$ Depoimento de Padre Roque Patussi, entrevista realizada por AZEVEDO, Flávio Antonio Gomes de; MARQUE, Roberta Vaz De no Centro de Estudos Migratório da Pastoral dos Migrantes Latino-americanos.

${ }^{7}$ Maria Cristina Cacciamali define o processo de informalidade da seguinte maneira: “... processo de mudanças institucionais que deriva das transformações estruturais na produção e no emprego, que são impulsionadas pela liberalização do comércio, pela maior integração das economias à economia mundial e pela revolução tecnológica em andamento. $\mathrm{Na}$ dimensão do mercado de trabalho, o processo de informalidade se revela por meio da destruição, adaptação e redefinição de um conjunto de instituições, normas e regras - estabelecidas juridicamente ou por meio de práticas consuetudinárias, envolvendo os seguintes aspectos: as relações entre as empresas para organizar a produção e sua distribuição; os processos de produção e de trabalho; as formas de inserção de trabalho; as relações de trabalho; e os conteúdos das ocupações. Essas alterações se mostram por meio de um duplo um duplo efeito. De um lado, são os processos de corrosão de determinadas práticas ou instituições que se tornam inadequadas pela perda de sua eficácia e/ou de sua legitimidade política ou por envolver custos diretos ou indiretos elevados. Por outro lado, constituem os processos que definem ou adaptam normas, práticas, procedimentos e instituições às necessidades e interesses da sociedade contemporânea." (CACCIAMALI, 2003).
} 
em vista o fracasso no emprego de força de trabalho nativa recai sobre o trabalhador boliviano desde meados da década de 1980. A sua procedência de regióes extremamente pobres, submissão, disposição para longas jornadas de trabalho, e a sua habilidade na costura e na tecelagem tornam essa máode-obra extremamente atraente. Um elemento adicional completa o quadro, sendo clandestino, o trabalhador imigrante, não pode recorrer à Justiça do Trabalho nem obter a salvaguarda de outras leis brasileiras.

A entrada clandestina de emigrantes bolivianos aumenta ao longo dos anos de 1990. A partir de entáo, a indústria do vestuário continua sendo dominada pela comunidade coreana, que pratica em geral contratos triangulares de trabalho. ${ }^{8}$ A condição de agenciador ou empreiteiro em geral é assumida por um boliviano, por vezes clandestino, mas também pode ser assumida por um brasileiro. O Diagrama 1 ilustra as diferentes relações contratuais de uma oficina de confecções nessa situação.

\footnotetext{
${ }^{8}$ Segundo Cacciamali e Chahad (2005): "A relação de emprego tradicional envolve normalmente duas partes: o empregador e o empregado. A observação, contudo, da experiência recente de inúmeros países indica um conjunto de situações mais complexas de relações de emprego, mas em grande proporção envolvendo uma terceira parte, daí a denominação de relação "triangular" Define-se: "Uma relação de emprego "triangular" ocorre quando os empregados de uma empresa (provedora) desempenham seu trabalho para uma terceira parte (empresa usuária) para quem o seu empregador oferece trabalho e outros serviços", e "Uma ampla variedade de contratos é utilizada para formalizar a oferta desses serviços". Tais contratos podem ter efeitos benéficos para os empregados em termos de oportunidades de emprego, experiência adquirida e desafios profissionais. Do ponto de vista legal, contudo, estes contratos podem representar dificuldades técnicas ao trabalhador, pois ele pode ter que interagir com dois (ou mais) interlocutores, cada um dos quais assumindo certas funções de um empregador tradicional. A relação de emprego "triangular" pode assumir várias formas, sendo a mais usual a subcontratação, terceirização, ou então a utilização de agências de emprego privadas. Outro arranjo muito comum é o sistema de franchising, onde uma empresa cede a marca à outra empresa, em principio em bases independentes. Contudo, 0 adquirente sempre contrai obrigações financeiras com a concedente, que acaba exercendo controle sobre o mesmo, inclusive em decisões relativas ao uso de pessoal. Vejam-se CACCIAMALI; CHAHAD (2005) e INTERNATIONAL LABOR ORGANIZATION (2003).
} 
Diagrama 1 - Relaçôes de trabalho triangulares nas oficinas de confecção cidade de São Paulo, 2004.

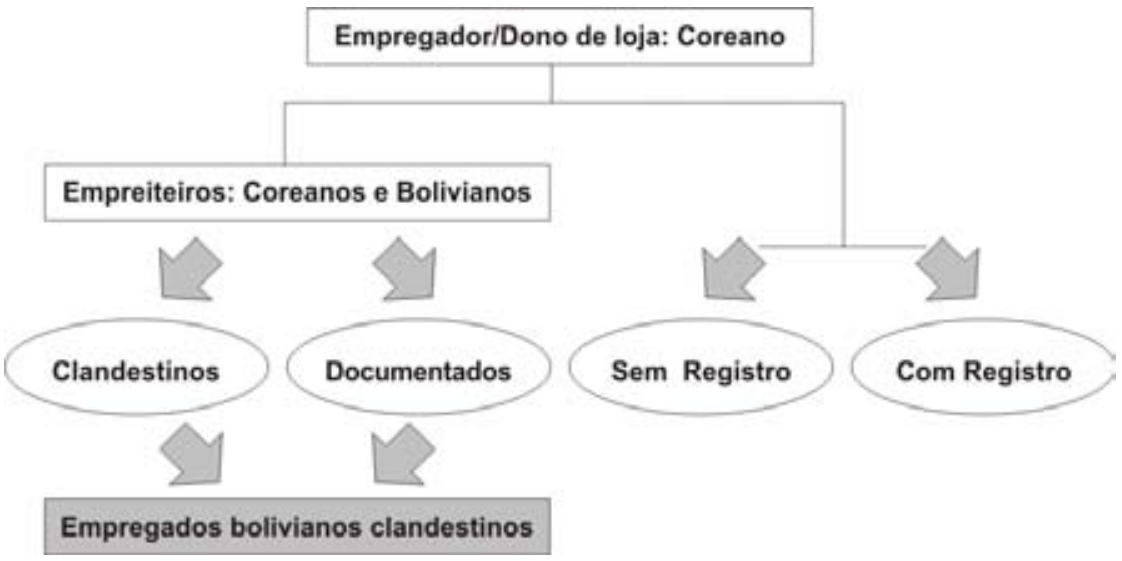

FONTE: Elaboração dos autores.

Os trabalhadores são recrutados nas cidades de Santa Cruz de la Sierra, La Paz e Cochabamba, que funcionam como pólos receptores dos emigrantes procedentes das regióes andinas mais pobres da Bolívia onde as atividades econômicas mercantis são muito reduzidas. Nessas localidades o recrutamento é realizado por várias mídias nas cidades de maior porte e de redes de contatos informais nas vilas andinas. No início da viagem, o agenciador apreende os documentos dos emigrados. A viagem é realizada principalmente pelo Paraguai, onde os emigrantes aguardam em ninhos o momento para atravessar a fronteira pela Ponte da Amizade. Durante a espera muitas vezes não há comida ou água. A viagem para São Paulo é realizada de ônibus. A viagem também pode ser realizada através da região de Corumbá ou da regiáo amazônica.

A população andina possui uma tradição de associativismo, usualmente expressa por meio de organizaçóes de características religiosas, culturais e/ou de trabalho. ${ }^{9} \mathrm{O}$ emigrante é conduzido de seu local de origem para um enclave étnico, onde é encerrado entre seus pares. O que vale é a sua relação de fidelidade e de reciprocidade com o agenciador e/ou empreiteiro. Quem o trouxe pagou todos os gastos de seu transporte, ele retribui sob a forma de trabalho.

\footnotetext{
${ }^{9}$ Segundo Pe. Roque Patussi, do Centro de Pastoral dos Migrantes, há mais de oitocentos times de futebol de bolivianos organizados em 30 ligas na grande São Paulo (BESSEGIO, 2005).
} 
Tendo como ponto de referência as relaçóes sociais do local de origem, ele no Brasil se encontra numa situaçáo de menor pobreza do que antes. $\mathrm{O}$ agenciador/empreiteiro the oferece uma oportunidade de trabalhar, de juntar dinheiro e de melhorar de vida: na realidade, está lhe fazendo um favor (MARTINS, 1997).

Desse modo, as relaçôes entre os costureiros das oficinas de confecção e o empregador muitas vezes podem ser caracterizadas como familiares ou de compadrio, estabelecendo-se e evoluindo em uma condição ambígua de fidelidade e de sobrexploração.

A relaçáo tanto pode evoluir para o tipo servidão por dívida ou dirigir-se para uma relaçáo paternalista. $\mathrm{O}$ trabalhador só vai receber o dinheiro pelo seu trabalho quando for embora pelo término do vínculo ou devido a uma emergência, por exemplo, um problema de família.

A sobrexploração é suportada porque ocorre no meio de uma relação familiar. $\mathrm{O}$ empregador no local de destino é a conexão com a sua família original, que nesse local faz muitas vezes o papel de sua família.

Em nome da fidelidade e da possibilidade de trabalhar, o imigrante clandestino exerce um contrato de trabalho verbal no qual ele é remunerado por peça, totalizando um salário-hora muito abaixo da máo de obra local e exercendo uma jornada extensa de trabalho, que pode atingir 16 ou 18 horas por dia. Por vezes paga parceladamente a compra da máquina de costura que usa na oficina, obrigando-o a trabalhar com maior intensidade para perceber alguma remuneração em dinheiro. ${ }^{10}$

O empreiteiro terceirizado também sofre restrições na sua remuneração, na medida em que o contratante, como garantia, deixa sempre pendente o pagamento de uma encomenda. Por exemplo, a remuneração da primeira encomenda é paga quando o empreiteiro entrega a segunda, e assim por diante. Antes de efetuar o pagamento aos trabalhadores, o empreiteiro tem que fazer frente aos outros gastos, como aluguel, alimentos, utilidades públicas, manutenção e depreciação das máquinas, bem como fazer um fundo para resistir aos períodos sem trabalho assim, a remuneração dos trabalhadores é comprimida.

A atividade é clandestina, de modo que o trabalhador costura em um ambiente inadequado, em galpóes sem janelas ou porões respirando o pó

\footnotetext{
${ }^{10}$ Entrevistas no campo apontam que o imigrante recém ingressado necessita de pelo menos 12 meses para quitar os custos de seu deslocamento.
} 
gerado pela grande quantidade de tecido que será transformado em peças. Ele vive no mesmo local dormindo sobre um colchonete, que estende atrás de sua máquina de costura, em uma situação abaixo de condiçôes mínimas, sem refeitório e um banheiro coletivo.

A intensidade do trabalho, a má alimentação e a promiscuidade constituem o caldo ideal para doenças como a tuberculose, doenças sexualmente transmissíveis, bem como para gravidez precoce entre outros agravos à saúde.

A anistia oferecida em 1998 pelo governo brasileiro para os imigrantes clandestinos atraiu profissionais liberais e outros imigrantes já estabilizados, porém, não sensibilizou a grande maioria dos clandestinos que trabalha nas oficinas de costura. Entre as razóes alegadas, durante as entrevistas, encontrase o medo que o patrão o denunciasse à Polícia Federal ou que fosse demitido. Segundo Sidnei Silva o sonho de todo trabalhador que esta na oficina é juntar dinheiro, ficar no Brasil, continuar no ramo e tornar-se também um proprietário, dono de oficina (SILVA, 1995). Reproduzindo, provavelmente, as relaçóes de recrutamento e trabalho que lhe foram oferecida/imposta pelo seu compatriota.

Os trabalhadores bolivianos há mais tempo no país que se encontram estabelecidos fora das oficinas são recrutados em praça pública. Na Praça Kantuta, no Pari, bairro da cidade de São Paulo, proprietários de oficinas, na sua grande maioria, bolivianos e coreanos, e trabalhadores bolivianos se encontram. Em praça pública, fazem-se as contrataçóes e estabelecem-se as remuneraçóes.

O Brasil não está menos sujeito que os demais países do globo que padecem da presença de uma sofisticada rede dedicada ao tráfico de seres humanos, cujo destino parece ser principalmente o antigo centro industrial da cidade de São Paulo no norte da zona leste, Pari, Brás e Bom Retiro, e suas adjacências, como São Miguel Paulista.

Hipoteticamente estamos falando da existência de redes de tráfico humano que assolam todo o planeta atuando num setor específico da economia brasileira, o ramo das confecçóes, no qual proprietários de confecçóes aqui estabelecidos, principalmente coreanos ou bolivianos, contratam recrutadores para incitar e motivar a vinda de trabalhadores com promessas de emprego, moradia, alimentação e bons salários. 


\section{Considerações finais}

Ao mesmo tempo em que o processo de globalização não foi capaz de gerar empregos na América do Sul, aumenta a desigualdade de renda entre os países ricos e pobres e passa a evidenciar os hábitos de consumo e estilos de vida dos países ricos através das mídias. A insatisfação com relação ao seu país de origem aumenta entre a população dos países mais pobres, impulsionando fluxos emigratórios, inclusive muitas vezes fugindo da miséria. ${ }^{11}$

O crescente fluxo de deslocamento humano passa a ser uma realidade global preocupante, sendo recriminado, embora necessário, complexo e de difícil caracterização. Paradoxalmente, a opção contemporânea pela mobilidade social procura atender a demanda de mão-de-obra não qualificada dos países centrais para os setores de agricultura, alimentação, construção, têxtil e vestuário. Bem com nos serviços domésticos, nas ocupaçóes de cuidador, e outros serviços pessoais. A função da mão-de-obra imigrante na divisão social do trabalho nos países mais ricos é exercer os trabalhos mais pesados, indesejados e de maior risco, que a comunidade local se recusa a desempenhar.

As emigraçóes internacionais se constituem em um tema de amplo interesse da comunidade internacional, gerando motivos na maioria das vezes de repressão e de alta recriminação. No entanto o recrudescimento das restriçóes legais à emigração internacional encoraja mecanismos de abuso da exploração humano - mais especificamente, fortalece as redes de tráfico humano e os dispositivos escusos de facilitação de entrada nos países de destino, germinando a violência, a corrupção e a criminalidade. ${ }^{12}$

A preocupação internacional pode ser justificada pelo caráter humanitário, sobretudo porque o desdobramento natural desse processo acaba sendo a subserviência, ou seja, a exploração é praticada através de formas de emprego que escapam das normas laborais vigentes internacionalmente. ${ }^{13}$ Tampouco a adesão aos compromissos e aos dispositivos internacionais de combate ao

${ }^{11}$ OIT: Não ao trabalho forçado, Relatório I(B), Relatório Global do Seguimento da Declaração da OIT relativa a Princípios e Direitos Fundamentais no Trabalho, Conferência Internacional do Trabalho, 89 $9^{\circ}$ Reunião, Genebra, OIT, 2001.

${ }^{12}$ A literatura internacional utiliza os seguintes termos: trafficking e smuggling. Veja-se, por exemplo, www.ilo.org/ declaration ou www.ilo.org/migrant.

${ }^{13}$ Lembramos que a escravidão é proibida pelo sistema internacional de proteção de direitos humanos a cargo da Organização das Nações Unidas - ONU, pelo corresponde sistema regional americano, a cargo da Organização dos Estados Americanos - OEA, e por organizações especializadas por área de ênfase, como a Organização Internacional do Trabalho - OIT. 
referido problema conseguem impedir a sua ocorrência, tendo em vista as causas econômicas e sociais que o promovem.

Náo obstante, para os emigrantes pobres, optar pela mobilidade social significa aceitar as próprias carências e, num ato de coragem ser capaz de enfrentar todas as dificuldades do processo do deslocamento humano, para se conseguir uma vida melhor. Portanto, a busca por melhores condiçóes de vida supera o mero caráter de aceitação voluntária, única e exclusivamente para se fugir da miséria. Trata-se, antes de qualquer coisa, da aceitaçáo da própria vontade de ascensão social, do reconhecimento de sucesso por seus pares, do sentimento de realização e, por que náo dizer, da chance de dar oportunidade à ambição. Daí vem o caráter volitivo do fenômeno e não voluntário como muitos especialistas sobre o tema defendem. 


\section{Referências Bibliográficas}

ALEXANDRE, Roberto. Enquanto houver miséria, o tráfico continuará com as mulas. Disponível em: http://www.folhadaregiao.com.br/rota_das_mulas/5. php. Acesso em: dezembro de 2005.

AZEVEDO, Flávio Antonio Gomes de. A presença de trabalho forçado na cidade de São Paulo: Brasil/Bolivia. São Paulo, 2005. Dissertação (Mestrado em Integração da América Latina) - Programa de Pós-Graduação em Integração da América Latina da Universidade de São Paulo - PROLAM/USP, 2005.

BESSEGIO, Luiz. Imigrantes: trabalhando como escravos? Disponível em: http://www.adital.com.br/site/noticias/12646.asp?lang=PT\&cod=12646. Acesso em: dezembro de 2005.

CACCIAMALI, Maria Cristina. Princípios e direitos fundamentais no trabalho na América Latina. São Paulo em Perspectiva, São Paulo, v. 16, n. 2, 2002.

CACCIAMALI, Maria Cristina; AZEVEDO, Flávio Antonio Gomes de. Dilemas da erradicação do trabalho forçado no Brasil. In: CHAHAD, José Paulo Zeetano; CACCIAMALI, Maria Cristina. Mercado de trabalho no Brasil: novas práticas, negociaçóes coletivas, e direitos fundamentais no trabalho. São Paulo: Editora LTr, 2003.

CACCIAMALI, Maria Cristina. A desfiliação do estatuto do trabalho na década de 1990 e a inserção dos ocupados que compóem as famílias de menor renda relativa. In: CHAHAD, José Paulo Zeetano; PICCHETTI, Paulo. Mercado de trabalho no Brasil. Padróes de comportamento e transformaçôes institucionais. São Paulo: LTr, 2003.

CACCIAMALI, Maria Cristina; CHAHAD, José Paulo Zeetano. As transformaçóes estruturais no setor rodoviário e reorganização no mercado de trabalho do motorista de caminhão no Brasil. In: Anais do IX Encontro Nacional da ABET, UFPE, Recife, 2005. Disponível em: http://www.abet. clic3.net/. Acesso em dezembro de 2005.

CENTRO DE ESTUDOS MIGRATÓRIOS - CEM. Disponível em: http:// www.cemsp.com.br. Acesso em: novembro de 2005. 
CENTRO DE ESTUDOS MIGRATÓRIOS - CEM. Entrevista realizada por AZEVEDO, Flávio Antonio Gomes; MARQUE, Roberta Vaz de com Padre Sidnei Marco DORNELAS, São Paulo, 3 de maio de 2004.

INTERNATIONAL LABOR ORGANIZATION, The scope of the employment relationship, 91 Session, Report V, Fifth Item on the Agenda. Genebra: International Labor Office, 2003.

KEUM, Joa Choi, Além do arco-íris: a migração coreana no Brasil. São Paulo, 1991. Dissertação (Mestrado em História Social) - Faculdade de Filosofia, Letras e Ciências Humanas da Universidade de São Paulo, 1991.

MARTINS, José de Souza. Fronteira: a degradação do outro nos confins do humano. São Paulo: HUCITEC, 1997.

ORGANIZAÇÃO INTERNACIONAL DO TRABALHO - OIT. Declaração da OIT sobre os principios e direitos fundamentais. Genebra: OIT, 1998.

ORGANIZAÇÃO INTERNACIONAL DO TRABALHO - OIT. Não ao trabalho forçado. Relatório global do seguimento da Declaração da OIT relativa aos Princípios e Direitos Fundamentais no Trabalho. Genebra: OIT, 2001.

ORGANIZAÇÃO INTERNACIONAL DO TRABALHO - OIT \& BRASIL. SECRETARIA DOS DIREITOS HUMANOS, Aperfeiçoamento legislativo para o combate ao trabalho escravo. Brasília: OIT/SDH, 2002.

ORGANIZAÇÃO INTERNACIONAL DO TRABALHO - OIT. Disponível em: http://ww.ilo.org/declaration. Acesso em: novembro de 2005.

ORGANIZAÇÃO INTERNACIONAL DO TRABALHO - OIT, Disponível em: http://www.ilo.org/migrant.

ORGANIZAÇÃO DAS NAÇÓES UNIDAS - ONU, Protocolo contra o contrabando de migrantes por terra, mar e ar, complemento da Convenção das Naçóes Unidas contra o crime organizado transnacional, Nova Iorque: ONU, 2000.

PASTORAL DOS MIGRANTES, Disponível em: http://www.cpmigrantes. com.br/quemsomos.htm. Acesso em: novembro de 2005. 
PASTORAL DOS MIGRANTES. Entrevista realizada por AZEVEDO, Flávio Antonio Gomes de; MARQUE, Roberta Vaz de com Padre Roque PATUSSI; Ruth CAMACHO. São Paulo, 20 de maio de 2004.

PATARRA, Neide L. (Coord.). Emigração e imigração internacionais no Brasil contemporâneo. Campinas: FNUAP, volume 1, 1995.

SILVA, Sidnei. Costurando sonhos: etnografia de um grupo de imigrantes bolivianos que trabalham no ramo da costura em São Paulo. São Paulo, 1995. Dissertação (Mestrado em Integração da América Latina) - Programa de Pós-Graduação em Integração da América Latina da Universidade de São Paulo - PROLAM/USP, 1995. 